
\title{
Zs Research Square \\ Predicting Prevention of Cigarette Smoking in Youth: Using Multi-Theory Model (MTM)
}

\section{Hamid Abasi}

Aja University of Medical Sciences https://orcid.org/0000-0002-5696-4859

Zahra Sadat Asadi ( $\nabla$ zasadi@ajaums.ac.ir)

Aja University of Medical Sciences https://orcid.org/0000-0002-9193-046X

\section{Naser Mohammad gholi Mezerji}

Hamadan University of Medical Sciences School of Public Health

\section{Research}

Keywords: Cigarette Smoking, Youth, Prevention, Multi-Theory Model

Posted Date: August 12th, 2020

DOI: https://doi.org/10.21203/rs.3.rs-56298/v1

License: (a) This work is licensed under a Creative Commons Attribution 4.0 International License. Read Full License 


\section{Abstract}

Background: Cigarette smoking (CS) is the most important cause of death and disability in the world and is a complex behavior that is affected by various factors. This study was aimed to test the ability of MTM to predict preventing CS in youth.

Methods: In this cross-sectional study, 230 youth who were volunteer to do military services as a soldier were selected by simple random sampling in 2019, western Iran. Data collection were performed by using questionnaire demographic characteristics and MTM constructs of CS. The obtained data were analyzed using descriptive statistics, logistic regression, and Hosmer-Lemeshow test in SPSS 20 software.

Results: In this study, the Mean ( \pm SD) age of the participants was $21.13( \pm 0.89)$. The prevalence of current cigarette smoking (CCS) and ever cigarette smoking (ECS) was $12.2 \%$ and $23 \%$, respectively. The results of the logistic regression test showed that ECS $(p<0.001)$ and having a family member smoker $(p=0.026)$ were predictor factors for CCS. Sustenance of preventing CS behavior was predicted by constructs of emotional transformation $(p=0 / 006)$, practice for change $(p=0=022)$, and changes in the social environment $(p<0.001)$.

Conclusions: MTM shows that it is a reliable and useful theory in the sustenance of preventing CS behavior in youth who volunteer to do military services as soldiers. Therefore, this robust theory should be tested in designing, implementing, and evaluating of CS prevention interventions.

\section{Background}

Cigarette smoking (CS) is one of the leading causes of cancers and provides areas for heart arrest, respiratory infections, peptic ulcers, and depression [1]. Even smoking a cigarette daily increases the risk of cancer and cardiovascular disease [2]. By 2030, 70 percent of annual deaths from smoking worldwide are expected to occur in developing countries [3].

Various studies have shown that both in developed and developing countries, the prevalence of smoking among youth is increasing and the age of onset has been declining $[3,4]$. Smoking is so prevalent in the United States that $15 \%$ of adults in the United States are active smokers [5]. The prevalence of CS in the Iranian population aged 15 to 64 is $15.3 \%$ [6]. Another study estimated the prevalence of CS (ever and current) among aged 15 to 64 is $12.5 \%$, compared with $4.23 \%$ for men and $1.4 \%$ for women [7]. Early-onset of smoking is very worrying, so it is a significant predictor of smoking in adulthood [8]. If regular smoking is started in early adolescence and adolescence, there is a 50 percent chance of premature death from smoking-related diseases [3]. There is no single cause for the onset of smoking in adolescents and young adults, but smoking is a multicausal behavior that is related to psychosocial, biochemical, and economic-political factors [9]. Several studies have cited several factors as risk factors for $\mathrm{CS}$, including low socioeconomic status, having friend smoker and peer pressure, and the quality of parental responsiveness to social needs during adolescence, non-adherence to religious issues and broken family relationships, mental illness, alcohol abuse, drug addiction/abuse, age, education, gender, race/ethnicity and poverty [10-12]. MTM is a new model proposed for changes in health behaviors $[13,14]$. This model generally divides behavior into two parts: initiation and maintenance. To initiate change in health behavior, constructs such as participatory dialogue(more weight advantages than disadvantages of changing health behavior), behavioral confidence(perceived behavioral control and self- 
efficacy), and changes in the physical environment(availability of resources) are influential, also constructs such as emotional transformation(controlling feelings and directing them), practice for change(reflection and focus on behavior), and changes in the social environment (role of friends and family) are also effective in maintaining a healthy behavior [13-15] (Figure1). This theory examines and tests behavior change from cognitive, semantic, and environmental aspects [13]. The results of studies on CS show that the prevalence of this negative health behavior among young people is high and In general, it is important to note that epidemiological studies identify the determinants of high-risk behaviors such as CS and water-pipe smoking, and examine these determinants before designing and implementing interventions $[1,16]$. Therefore, the present study was conducted to evaluate the prediction of MTM to understand the prevention CS behavior in youth in 2019.

\section{Methods}

In this cross-sectional study, 230 youth who were ready to start military service were selected by simple random sampling from 5 groups. Given that previous studies have reported different prevalence values, to determine the sample size, the prevalence of CS in youth in a study was $\% 21$ [9] and with $95 \%$ confidence level and 5\% accuracy, The sample size was calculated 238. The response rate in this study was 96.6 . The word criteria studied in this study were: 1 youth, who volunteer to do military service as soldier, 2 . Lack of physical or mental illness, as determined by the researcher, 4 .reading and writing literacy, and 5. to fill out the written consent. The exclusion criteria were: 1 . dissatisfaction in completing the questionnaire and 2. Having mental and physical illness.

\section{Instrument}

The data collection tool in this study consisted of two parts: demographic information and the constructs of MTM. Demographic variables such as age, education (less than $<$ Diploma/Diploma/ Associate/ Master of Science and upper), marital status (single/married), native (yes/no), ECS (yes/no), CCS (yes/no), having a smoking friend (yes/no), a family member of CS (yes/no) and hookah smoking (yes/no) were asked. For investigating constructs of MTM, a questionnaire was used including 38-item. Cronbach's alpha coefficient was 0.91. In order to assess the face validity and content of the questionnaire, the opinions of ten experts in the field of health education and promotion were used. Participatory dialogue was assessed with eight questions, four questions for investigating advantages. For instance, "if I do not smoke cigarettes, I will "be healthy" and four questions for investigating disadvantages, for example, "if I do not smoke cigarettes, I will "have fewer friends". The response ranged from completely disagree $(=1)$ to completely agree $(=5)$. By summing each question, the total score of the participatory dialogue was obtained (ranging from 4 to 20 units). The difference between the advantages and disadvantages scores the total score of the participatory dialogue.

The construct of behavioral confidence was calculated by seven questions. For instance, "Preventing smoking depends on my will." The response ranged from completely disagree $(=1)$ to completely agree $(=5)$. By summing each question, the total score of the behavioral confidence was obtained (ranging from 7 to 35 units). The construct of changes in physical environment was calculated with six questions. For example, "Cheap cigarettes make me smoke". The responses ranged from completely disagree $(=1)$ to completely agree $(=5)$. By 
summing each question, the total score of the changes in the physical environment (ranging from 6 to 30 units).

For assessing the initiation of preventing CS, the question of "I am sure I will prevent my CS in the coming weeks" were asked. The responses ranged from not at all likely $(=1)$ to completely likely $(=4)$. The emotional transformation was assessed by six questions. For instance, "I can manage the feeling of wanting to smoke a cigarette." The responses ranged from completely disagree $(=1)$ to completely agree $(=5)$. By summing each question, the total score of the emotional transformation was obtained (ranging from 6 to 30 units).

The construct of practice for change was calculated by five questions. For example, "Planning to prevent CS is important to me". The responses ranged from completely disagree $(=1)$ to completely agree $(=5)$. By summing each question, the total score of the practice for change was obtained (ranging from 5 to 25 units). For assessing changes in the social environment construct, six questions were asked. For example, "How confident are you that you can get help from best friends to prevent CS?" The responses ranged from not sure at all (=1) to completely sure $(=5)$. By summing each question, the total score of the changes in the social environment was obtained (ranging from 6 to 30 units).

For assessing the sustenance of preventing CS, The question of "How likely is it that you will prevent your CS from now on?" were sked. The responses ranged from not at all likely $(=1)$ to completely likely $(=4)$. The questionnaire completion time was 10-15 minutes. At the beginning of the study, the aims of the study were stated to the participants, and after obtaining written consent, participants completed the self-report questionnaire. This study was approved by the Ethics Committee of the Aja University of Medical Sciences.

\section{Data Analysis:}

The constructs of the MTM were considered as independent variables, and the initiation and maintenance of CS prevention behavior were considered as dependent variables. Data analysis were performed by using SPSS software version 20 and descriptive tests (the measuring of mean, standard deviation and frequency of data), the Hosmer-Lemeshow test (for the goodness of fit for logistic regression model) and regression analysis (the relationship between the dependent and independent variables). The Significance level was considered less than 0.05 .

\section{Results}

Most of the study participants (66.1\%) were 19 to 22 years. The mean $( \pm S D)$ of the age of the participants in this study was $21.13( \pm 0.89)$. About $49.1 \%$ of them were Diploma holders. In terms of marital status, 202 $(87.7 \%)$ were single. 126 (54.8) of participants were born at the beginning of military service. A total of 53 (23\%) of participants had smoked cigarettes in their past life. Also 28 (12.2\%) of participants were current cigarette smoker. A total of $62(27.7 \%)$ of participants had cigarette smokers in their families (Table 1).

Table 2 shows the descriptive information of the constructs of the MTM. The construct of advantages with the mean of 17.67 units (SD: \pm 3.43 ) shows that the youth's attitude towards CS prevention has been useful. The construct of disadvantage with the mean of 13.32 units (SD: \pm 5.29$)$ shows that youth understand the higher disadvantages of CS prevention. Based on a mean of 27.13 units (SD: \pm 4.76$)$ shows that youth were in a high 
level of ability to prevent CS. The initiation of behavior means the score was 2.87 units (SD: \pm 1.27 ,) which demonstrate that the youth were likely to prevent smoking cigarette in the upcoming weeks. Given the average score of 24.70 units (SD: \pm 5 ) for the structure of emotional transformation, it seems that youth manage and control their emotions well for not CS. Regarding the average score of 19.60 units (SD: \pm 4.30$)$ structure of practice for change, the average obtained indicates that the participants maintained their CS prevention behavior well.

Regarding the score of 16.67 units (SD: \pm 6.92 ) obtained from the structure of changes in the social environment, participants had a low-level of help from friends, family, and social environment. The sustenance

behavior had a mean of 2.89 units (SD: \pm 1.12 ) which demonstrate that the youth were likely to prevent smoking cigarette on a long-term basis. Also, among the demographic factors, only ECS $(P<0.001)$ and having a smoker family member $(p=0.026)$ were predictors of CS in youth (Table 3 ).

Table 4 shows the results of regression analysis on the initiation and maintenance of smoking prevention behavior according to the MTM. For initiation of preventing CS, the constructs of participatory dialogue $(P=0.341)$, behavioral confidence $(P=0.491)$, and changes in the physical environment $(P=0.298)$ were not significant. But, the motional transformation $(P=0.006)$, practice for change $(P=0.022)$, and changes in the social environment $(P<0.001)$ were significant in preventing CS sustenance among youth.

\section{Discussion}

This study aimed to assess the extent of MTM constructs to predict the prevention of CS behavior in youth. The MTM successfully predicted sustaining of preventing CS among 230 youth who were volunteers to do military services as soldiers. The emotional transformation is one of the sustenance constructs that was found as a predictor of sustaining to prevent CS among youth. To help change health-related behaviors, the ability to direct and control emotions in the direction of the goal is very important [17]. The results of various studies in consist with the results of our study show that the characteristics of pleasure from smoking from the perspective of smokers indicate the tendency and desire of people to smoke [18-20]. The tendencies and willingness of young people related to smoking can be rooted in their favorable and positive attitude towards smoking. Therefore, in interventions based on smoking prevention, it seems that the emotional aspects that emphasize on changing the positive attitude to the negative attitude of smoking can be helpful. One of the other sustenance constructs is practice for change that was found as a predictor of sustained preventing CS among youth. Self-regulation or self-monitoring is a process of internal control of individuals that initiates purposeful behaviors and gives individuals the ability to control their thoughts and behaviors toward the goal [21]. Bashirian's et al study showed that practice for change predicted to reduce water-pipe smoking among male students [20] and it is consistent with the result of our study. It seems that by using the process of self-monitoring and self-regulation with the aim of prevention CS in young people, they can be guided to achieve the goal to personally increase the likelihood of CS prevention behavior. In the current study, the construct of changes in the social environment was predicted preventing CS maintenance among youth. When people are in a critical situation, the attention and help of family, friends, and social environment can provide social support such as emotional, material, and feedback for the person [22]. Other studies also have shown that the role of social environment in smoking is so important, and they have a vital role and persuasive for smoking prevention and cessation $[20,23,24]$. Therefore, in designing intervention programs, it is suggested that friends and family members be informed 
about the negative effects of CS so that they can warn youth about the negative consequences of CS. In regard to CS status among youth, this study showed that $23 \%$ of youth who were volunteer to do military services as a soldier had a lifetime of smoking. In a study by Ahmadi et al. $[25,26]$, which investigated the prevalence of CS, the prevalence of lifetime smoking was $22 \%$. A study by Hussain et al. [26] also showed that $20 \%$ of participants had a history of smoking during their lifetime, which is consistent with the results of the present study.

It can be inferred that CS among youth is considered to be an attractive, self-esteeming, and self-indulgent behavior, so smoking is experienced at this age before entering the military. Therefore, preventive interventions in schools and universities need to be designed to educate the negative effects of smoking on health, enhancing self-efficacy in avoiding smoking.

Another result of the present study was that CS rate among participants was $28 \%$. Yasmin et al. [27] Another result of the present study was that CS rate among participants was $28 \%$. Yasmin et al. $[28,29]$ reported a prevalence of CS $47 \%$ and $56 \%$, respectively, which is inconsistent with the results of the present study. Given the importance and critical age of starting to do military service and the likelihood of CS at this age as well as the fact that smoking is a psychological phenomenon, interventions based on CS cessation as part of healthrelated services for youth who are volunteer to do military services as a soldier are needed.

Limitations: Due to the fact that the present study is cross-sectional, it is not possible to create a causal relationship between MTM variables and prevention of CS in youth. The youth sustained preventing CS and factors to maintain preventing CS are circumstantial. In order to identify, determine the cause and effect relationships and provide better evidence, a longitudinal study should be considered in the future. Finally, Due to the nature of the cross-sectional studies that are based on the report in the form of a questionnaire, the actual behavior of individuals may be overestimated or underestimated. Finally, due to the satisfactory methodology and sampling method, the generalization of the results is limited due to the limited study to youth who are volunteer to do military services.

\section{Conclusions}

The findings of this current study indicated that CS by youth based on MTM is predictable by the emotional transformation, practice for change, and changes in the social environment. The maintenance structures in MTM are effective in the sustenance of preventing CS behavior in youth who were volunteer to do military services as soldiers and must be approved in the design, implementation and evaluation of future educational interventions. MTM seems to be an appropriate theory and framework to address the factors influencing youth' health decisions in CS prevention.

\section{Abbreviations}

Cigarette Smoking (CS), Current Cigarette Smoking (CCS), Ever Cigarette Smoking (ECS).

\section{Declarations}

\section{Acknowledgements}


We thank Aja University of Medical Sciences and all of participants.

\section{Authors' contributions}

HA and ZA contributed to conceptualization, methodology, data collection, project administration and were contributors to writing the manuscript. NM performed data analysis, interpreted the data and contributed to the study methodology. All authors read and approved the final manuscript.

\section{Funding:}

This work was supported by Aja University of Medical Sciences, Number grant (91000375).

\section{Availability of data and materials}

The datasets used and/or analyzed during the current study are available from the corresponding author on reasonable request.

\section{Ethics approval and consent to participate}

This study was approved by the Ethics Committee of the Aja University of Medical Sciences.

\section{Consent for publication}

Not applicable.

\section{Competing interests}

The authors declare that they have no competing interests

\section{References}

1. Barati, M., et al., Factors Associated With Tobacco Smoking Among Male Adolescents: the Role of Psychologic, Behavioral, and Demographic Risk Factors \%J Avicenna Journal of Neuropsychophysiology. 2015. 2(1): p. 18-24.

2. Inoue-Choi, M., et al., Association of Long-term, Low-Intensity Smoking With All-Cause and Cause-Specific Mortality in the National Institutes of Health-AARP Diet and Health Study. JAMA Intern Med, 2017. 177(1): p. 87-95.

3. Madani, A., et al., Prevalence of smoking and associated internal and external factors in high school students in Bandar Abbas, Iran \% J Journal of Preventive Medicine. 2016. 2(4): p. 39-49.

4. Mohammadkhani, S.R.J., . RELATIONSHIP BETWEEN CIGARETTE AND HOOKAH SMOKING WITH INDIVIDUAL, FAMILY AND SOCIAL FACTORS IN ADOLESCENTS. JOURNAL OF SABZEVAR UNIVERSITY OF MEDICAL SCIENCES, 2016. 23(2): p. -

5. Prevention., e.f.D.C.a., Current cigarette smokingamong adults in the United States. . Available at:https://www.cdc.gov/tobacco/data_statistics/fact_sheets/adult_data/cig_smoking/index.htm.Accessed May 13, 2020., 2020. 
6. Bagheri, M., N. Roozbahani, and M. Shamsi, Predictive Factors of Smoking among Adults Based on Transtheoretical Model \%J Iranian Journal of Health Education and Health Promotion. 2015. 3(3): p. 211-218.

7. Hazavei, M.m. and H. Abasi, The Role of Interventions in Reduction of Smoking in High School Adolescents: A Review Study \%J Qom Univ Med Sci J. 2016. 10(9): p. 89-103.

8. Sharifirad, G.R., et al., Perceived Threat about Cigarette Smoking among Adolescents: Optimistic Bias \% J Qom Univ Med Sci J. 2016. 10(4): p. 69-77.

9. Alireza Ayatollahi, S., A. Mohammadpoorasl, and A. Rajaeifard, Predicting the stages of smoking acquisition in the male students of Shiraz's high schools, 2003. Nicotine Tob Res, 2005. 7(6): p. 845-51.

10. Lotfi, Y. and A. Ayar, The Effects of Informative Programs on the Change of Attitude and Consumption of Drugs. Procedia - Social and Behavioral Sciences, 2012. 35: p. 195-204.

11. Pirdehghan, A., et al., Smoking frequency and modeling the underlying predicting factors of tobacco smoking among high school students in Yazd city, 2012 \% J Journal of Shahrekord Uuniversity of Medical Sciences. 2014. 16(5): p. 56-65.

12. Coleman, S.R.M., et al., Current cigarette smoking among U.S. college graduates. Preventive Medicine, 2019. 128: p. 105853.

13. Sharma, M., Multi-theory model (MTM) for health behavior change. 2015.

14. Sharma, M., Theoretical foundations of health education and health promotion. . Burlington, MA: Jones and Bartlett Learning, 2017.

15. Bashirian, S., et al., Male students' experiences on predictors of waterpipe smoking reduction: A qualitative study in Iran. Tobacco prevention \& cessation, 2019. 5: p. 30-30.

16. Bashirian, S., et al., The role of sociodemographic factors associated with waterpipe smoking among male adolescents in western Iran: A cross-sectional study. Tob Induc Dis, 2018. 16: p. 29.

17. Sharma, M., et al., Using multi-theory model to predict initiation and sustenance of small portion size consumption among college students. Health promotion perspectives, 2016. 6(3): p. 137-144.

18. Afifi, R., et al., Social norms and attitudes linked to waterpipe use in the Eastern Mediterranean Region. Soc Sci Med, 2013. 98: p. 125-34.

19. Baheiraei, A., et al., Factors that Contribute in the First Hookah Smoking Trial by Women: A Qualitative Study from Iran. Iranian journal of public health, 2015. 44(1): p. 100-110.

20. Bashirian, S., et al., Predicting to reduce water pipe smoking in male adolescents: using multi theory model (MTM). Journal of Substance Use, 2020. 25(1): p. 50-55.

21. Ston, orginator of theory. Prentico Haal University, 1985. NJ, P:239. .

22. Glanz K Rimer B, V.K., Health behavior and health education: theory, research, and practice (4th ed). , 2008.

23. Bashirian, S., et al., Water Pipe Smoking Reduction in the Male Adolescent Students: An Educational Intervention Using Multi-Theory Model. J Res Health Sci, 2019. 19(1): p. e00438.

24. Kotecha, S., M. Jawad, and S. Iliffe, Knowledge, attitudes and beliefs towards waterpipe tobacco smoking and electronic shisha (e-shisha) among young adults in London: a qualitative analysis. Prim Health Care Res Dev, 2016. 17(2): p. 166-74.

25. AHMADI, K., et al., EFFECTIVE FACTORS IN SMOKING AMONG SOLDIERS. 2011. 2(7): p. -. 
26. Hussain, N.A.A., M. Akande, and E.T.O. Adebayo, Prevalence of cigarette smoking and knowledge implications among Nigerian soldiers of its health. East African journal of public health, 2011. 7(1): p. 81-3.

27. Cypel, Y.S., et al., Cigarette Smoking and Sociodemographic, Military, and Health Characteristics of Operation Enduring Freedom and Operation Iraqi Freedom Veterans: 2009-2011 National Health Study for a New Generation of US Veterans. Public Health Rep, 2016. 131(5): p. 714-727.

28. Chen, F., et al., A Cross-Sectional Survey on Cigarette Smoking in the Chinese Navy. Military Medicine, 2018. 184(5-6): p. e211-e217.

29. Lopez, A.A., et al., Correlates of current and heavy smoking among U.S. soldiers returning from combat. Exp Clin Psychopharmacol, 2018. 26(3): p. 215-222.

\section{Tables}


Table 1.

Demographic information for participates $(n=230)$.

\begin{tabular}{|c|c|c|}
\hline Variables & & $\mathrm{n}(\%)$ \\
\hline \multirow[t]{2}{*}{ Age } & $19-22$ & $152(66.1)$ \\
\hline & $22-26$ & 78 (33.9) \\
\hline \multirow[t]{4}{*}{ Education } & $<$ Diploma & $57(24.8)$ \\
\hline & Diploma & $113(49.1)$ \\
\hline & Associate & $17(7.4)$ \\
\hline & MS and upper & $43(18.7)$ \\
\hline \multirow[t]{2}{*}{ Marriage statues } & Single & $202(87.8)$ \\
\hline & Married & $28(12.2)$ \\
\hline \multirow[t]{2}{*}{ Birthplace(Western Iran) } & No & $126(54.8)$ \\
\hline & Yes & $104(45.2)$ \\
\hline \multirow[t]{2}{*}{ Ever cigarette } & No & $177(77.0)$ \\
\hline & Yes & $53(23.0)$ \\
\hline \multirow[t]{2}{*}{ Current cigarette } & No & $202(87.8)$ \\
\hline & Yes & $28(12.2)$ \\
\hline \multirow[t]{2}{*}{ Family cigarette } & No & $168(73.0)$ \\
\hline & Yes & $62(27.0)$ \\
\hline \multirow[t]{2}{*}{ Friend cigarette } & No & $123(53.5)$ \\
\hline & Yes & $107(46.5)$ \\
\hline \multirow[t]{2}{*}{ Ever hookah smoking } & No & $134(58.3)$ \\
\hline & Yes & $96(41.7)$ \\
\hline
\end{tabular}




\section{Table 2:}

Descriptive statistics for constructs of the MTM, n=230

\begin{tabular}{|lllll|}
\hline Constructs & $\begin{array}{l}\text { Possible } \\
\text { range }\end{array}$ & $\begin{array}{l}\text { Observed } \\
\text { range }\end{array}$ & Mean & SD \\
\hline Initiation of preventing CS & 1 to 4 & 1 to 4 & 2.87 & 1.27 \\
\hline Advantages & 4 to 20 & 4 to 20 & 17.67 & 3.43 \\
\hline Disadvantages & 4 to 20 & 4 to 20 & 13.32 & 5.29 \\
\hline $\begin{array}{l}\text { Participatory dialogue (advantages - disadvantages } \\
\text { score) }\end{array}$ & -20 to 20 & -12 to 16 & 4.34 & 5.74 \\
\hline Behavioral Confidence & 7 to 35 & 14 to 35 & 27.13 & 4.76 \\
\hline Changes in Physical Environment & 6 to 30 & 11 to 30 & 21.54 & 4.67 \\
\hline $\begin{array}{l}\text { Sustenance of preventing CS } \\
\text { Emotional Transformation }\end{array}$ & 1 to 4 & 1 to 4 & 2.89 & 1.12 \\
\hline Practice for Change & 6 to 30 & 6 to 30 & 24.70 & 5 \\
\hline Changes in Social Environment & 5 to 25 & 5 to 25 & 19.60 & 4.30 \\
\hline
\end{tabular}


Table 3.

Logistic regression includes demographic variables and risk behaviors for predicting CCS $(n=230)$.

\begin{tabular}{|c|c|c|c|c|c|c|c|}
\hline \multirow[t]{2}{*}{ Variables } & \multirow[t]{2}{*}{ B } & \multirow[t]{2}{*}{ S.E. } & \multirow[t]{2}{*}{ Wald } & \multirow[t]{2}{*}{ Sig. } & \multirow[t]{2}{*}{$\operatorname{Exp}(B)$} & \multicolumn{2}{|c|}{ 95\% C.I.for EXP(B) } \\
\hline & & & & & & Lower & Upper \\
\hline Age & .680 & .863 & .621 & .431 & 1.975 & .364 & 10.725 \\
\hline Education & & & 5.240 & .155 & & & \\
\hline Education(1) & -.185 & 1.251 & .022 & .883 & .831 & .072 & 9.654 \\
\hline Education(2) & -1.661 & 1.091 & 2.316 & .128 & .190 & .022 & 1.613 \\
\hline Education(3) & -.257 & 1.170 & .048 & .826 & .773 & .078 & 7.664 \\
\hline Married & 1.396 & .877 & 2.534 & .111 & 4.039 & .724 & 22.529 \\
\hline Birthplace & .119 & .761 & .025 & .876 & 1.127 & .253 & 5.009 \\
\hline Ever cigarette & 3.955 & .843 & 22.040 & .000 & 52.221 & 10.015 & 272.289 \\
\hline Family cigarette & 1.658 & .746 & 4.934 & .026 & 5.249 & 1.215 & 22.672 \\
\hline Friend cigarette & -.732 & .865 & .716 & .397 & .481 & .088 & 2.622 \\
\hline Ever hookah smoking & .490 & .751 & .426 & .514 & 1.632 & .375 & 7.107 \\
\hline Constant & -7.567 & 2.550 & 8.803 & .003 & .001 & & \\
\hline
\end{tabular}

Hosmer and Lemeshow Test: $p=0.827$

Classification percent: $91.7 \%$,

Table 4:

The final regression model of preventing CS as predicted by constructs of MTM, $n=230$

\begin{tabular}{|llllll|}
\hline Constructs & B & SEB & $\boldsymbol{\beta}$ & 95\% Confidence Interval & P-value \\
\hline Initiation of preventing CS & & & & & \\
\hline Participatory dialogue & -0.025 & 0.905 & 0.976 & $(0.927$ to 1.026) & 0.341 \\
\hline Behavioral Confidence & 0.027 & 0.473 & 1.027 & $(0.951$ to 1.109) & 0.491 \\
\hline Changes in Physical Environment & 0.044 & 1.082 & 1.045 & $(0.961$ to 1.137) & 0.298 \\
\hline $\begin{array}{l}\text { Sustenance of preventing CS } \\
\text { Emotional Transformation }\end{array}$ & 0.146 & 7.451 & 1.157 & $(1.042$ to 1.285) & 0.006 \\
\hline $\begin{array}{l}\text { Practice for Change } \\
\text { Changes in Social Environment }\end{array}$ & 0.105 & 20.069 & 1.111 & $(1.061$ to 1.163) & 0.022 \\
\hline
\end{tabular}


$B=$ unstandardized coefficient; SEB = standard error of the coefficient; $\beta=$ standard coefficient

\section{Figures}
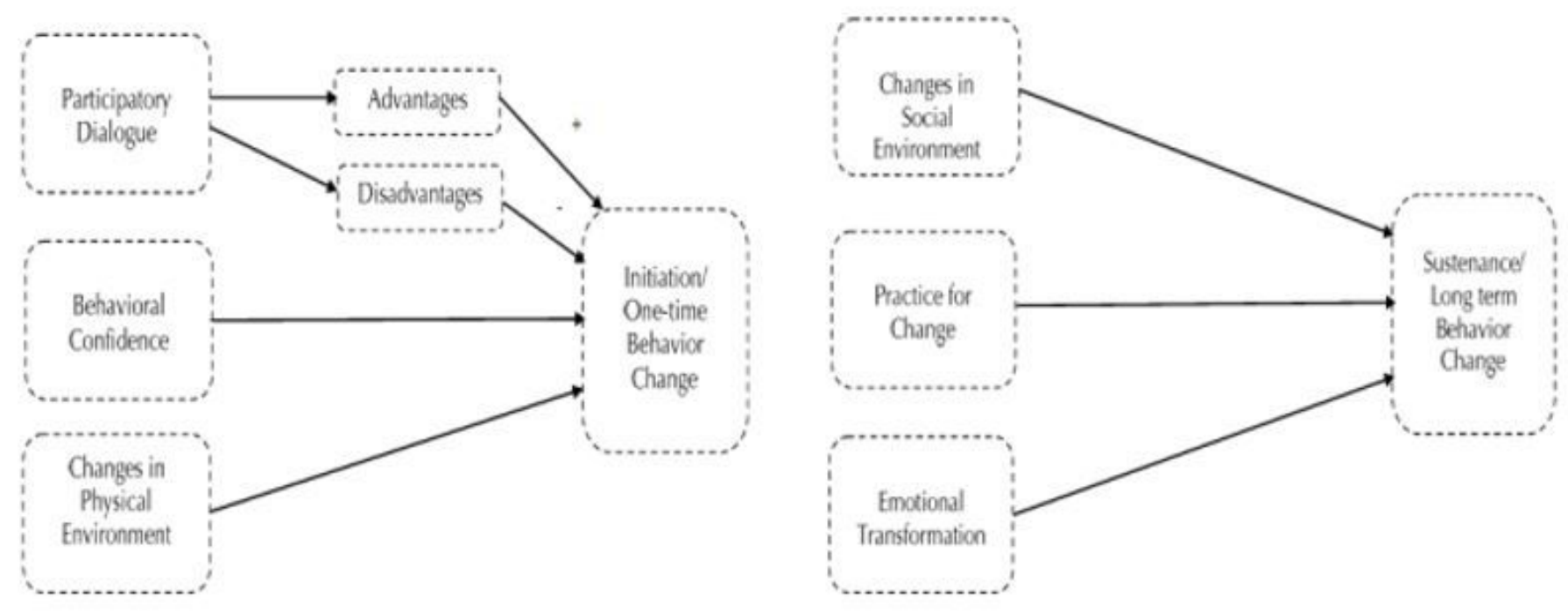

\section{Figure 1}

Conceptual framework of the MTM in initiating and maintaining health behavior change 